\title{
Estratégias de transição para alta hospitalar utilizadas por enfermeiros: revisão integrativa
}

Transition strategies for hospital discharge used by nurses: integrative review

Estrategias de transición para el alta hospitalaria utilizadas por los enfermeros: revisión integradora

\section{Valéria Cristina Lopes Gallo ${ }^{\mathrm{I}}$, Daiana Kloh KhalafI, Karina Silveira de Almeira Hammerschmidt ${ }^{\mathrm{III}}$, Mariane Lima Santiago ${ }^{\mathrm{IV}}$, Carine Vendruscolov}

\begin{abstract}
Resumo: Objetivo: identificar estratégias de transição do cuidado na alta hospitalar, utilizadas por enfermeiros para o fortalecimento da continuidade do cuidado, disponíveis na literatura científica. Método: revisão integrativa da literatura, que incluiu estudos completos, tendo como referência as estratégias "care transition" OR "Continuity of Patient Care" OR "care continuity" AND nurse para as bases de dados BVS, PubMed, SCOPUS e WoS e "care transition" OR "care continuity" AND nurse para CINAHL, publicados em inglês, espanhol ou português, entre 2016 e 2020, que responderam à questão de revisão. Resultados: foram selecionados 23 artigos, e as estratégias de transição do cuidado para a alta hospitalar usadas por enfermeiros para o fortalecimento do cuidado foram educação em saúde, reconciliação medicamentosa, telemonitoramento, planejamento da alta, contrarreferência e visita domiciliar. Conclusão: o enfermeiro é responsável pelo desenvolvimento de estratégias de transição interconectadas para o fortalecimento do cuidado, desenvolvendo ações diversificadas que qualificam a atenção.
\end{abstract}

Descritores: Enfermagem; Cuidado Transicional; Continuidade da Assistência ao Paciente; Alta do Paciente; Estratégias

\begin{abstract}
Objective: to identify strategies for the transition of care at hospital discharge, used by nurses to strengthen the continuity of care, available in the scientific literature. Method: integrative review of the literature, which included complete studies, based on the strategies "care transition" OR "Continuity of Patient Care" OR "care continuity" AND nurse for the databases VHL, PubMed, SCOPUS and WoS and "care transition" OR "care continuity" AND nurse for CINAHL, published in English, Spanish or Portuguese, between 2016 and 2020, which answered the review question. Results: 23 articles were selected, and the strategies for transition from care to hospital discharge used by nurses to strengthen care were health education, drug reconciliation, telemonitoring, discharge planning, counter-referral and home

\footnotetext{
${ }^{\text {I }}$ Enfermeira, Mestranda no Programa de Pós-Graduação em Prática do Cuidado em Saúde da Universidade Federal do Paraná (PPGENF/UFPR), Curitiba, Paraná, Brasil. E-mail: enf.valeria.gallo77@gmail.com, Orcid: https://orcid.org/0000-0003-1789-4998

II Enfermeira, Docente de Enfermagem da Universidade Federal do Paraná, Doutora em Enfermagem, Curitiba, Paraná, Brasil. E-mail: daianakloh@gmail.com, Orcid: https://orcid.org/0000-0001-5770-7523

III Enfermeira, Docente de Enfermagem da Universidade Federal do Paraná, Doutora em Enfermagem, Curitiba, Paraná, Brasil. E-mail: ksalmeidah@ufpr.br, Orcid: https://orcid.org/0000-0002-7140-3427

IV Acadêmica, bolsista de iniciação científica no curso de Enfermagem da Universidade Federal do Paraná, Curitiba, Paraná, Brasil. E-mail: marianels2010@outlook.com, Orcid: https://orcid.org/0000-0003-3492-2727

V Enfermeira, Docente de Enfermagem da Universidade do Estado de Santa Catarina, Doutora em Enfermagem, Chapecó, Santa Catarina, Brasil. E-mail: carine.vendruscolo@udesc.br, Orcid: https://orcid.org/0000-0002-5163-4789
} 
Estratégias de transição para alta hospitalar utilizadas por enfermeiros: revisão integrativa | 2

visit. Conclusion: nurses are responsible for developing interconnected transition strategies to strengthen care, developing diversified actions that qualify attention.

Descriptors: Nursing; Care Transition; Continuity of Patient; Patient Discharge; Strategies

Resumen: Objetivo: identificar estrategias para la transición de la atención al alta hospitalaria, utilizadas por los enfermeros para fortalecer la continuidad de la atención, disponibles en la literatura científica. Método: revisión integradora de la literatura, que incluyó estudios completos, basados en las estrategias "care transition" $O R$ "Continuity of Patient Care" OR "care continuity" AND "nurse" para las bases de datos BVS, PubMed, SCOPUS y WoS y "care transition" OR "care continuity" AND "nurse" para CINAHL, publicada en inglés, español o portugués, entre 2016 y 2020, que respondió a la pregunta de la revisión. Resultados: se seleccionaron 23 artículos, y las estrategias para la transición de la atención al alta hospitalaria utilizadas por los enfermeros para fortalecer la atención fueron la educación para la salud, la conciliación de medicamentos, la telemonitorización, la planificación del alta, la contrarreferencia y la visita domiciliaria. Conclusión: los enfermeros son responsables de desarrollar estrategias de transición interconectadas para fortalecer el cuidado, desarrollando acciones diversificadas que califiquen la atención.

Descriptores: Enfermería; Cuidado de Transición; Continuidad de la Atención al Paciente; Alta del Paciente; Estrategias

\section{Introdução}

A continuidade do cuidado em saúde é considerada essencial à assistência integral ao usuário do sistema de saúde, pois se refere ao atributo da Atenção Primária, que assegura a prestação da assistência necessária ao longo do tempo, ou seja, a longitudinalidade. ${ }^{1}$ A continuidade do cuidado feita pela integração de variadas dimensões, como as físicas, psicológicas e econômicas, proporciona melhorias na relação usuário e serviços de saúde. ${ }^{1-3}$

O usuário do sistema experimenta diversos momentos de tensão durante seu percurso em uma rede de atenção à saúde, necessitando de ações destinadas a assegurar a coordenação e a continuidade do cuidado, ${ }^{4}$ relacionadas à transição do cuidado. Esta é parte essencial da prestação de cuidados e envolve usuários, família e prestadores de serviços, podendo, quando adequada, proporcionar maior segurança e qualidade à jornada na malha assistencial. Entretanto, quando mal dimensionada, está relacionada a efeitos adversos graves como erros de medicação, atrasos no cuidado, duplicidade do tratamento, redução da adesão, piora na qualidade de vida, readmissões evitáveis, uso inadequado dos serviços e aumento do custo em saúde. ${ }^{4-5}$ No período pós-alta hospitalar, o usuário pode apresentar maior vulnerabilidade e risco de deterioração clínica. ${ }^{6}$

A busca pela continuidade do cuidado, garantida pela transição segura do cuidado e de 
3 | Gallo VCL, Khalaf DKK, Hammerschmidt KSA, Santiago ML, Vendruscolo C

qualidade, é destaque em vários países, em especial nos Estados Unidos da América (EUA) e em países da Europa, sendo impulsionada, inicialmente, para reduzir custos com reinternações evitáveis, ${ }^{5}$ estando comumente associada à melhoria da qualidade de assistência e de vida dos usuários. Nesse contexto, o enfermeiro tem sido o profissional envolvido nos processos de transição do cuidado por apresentar capacidade de identificação de pontos críticos do processo, planejamento da alta, envolvimento na reabilitação, educação em saúde e articulação na rede de atenção à saúde, ${ }^{4,7}$ fortalecendo a continuidade do cuidado após a alta hospitalar.

No Brasil, pesquisadores vêm desenvolvendo estudos e testando estratégias para o fortalecimento da continuidade do cuidado no cenário hospitalar e de transição para a atenção primária, especialmente na última década., ${ }^{4,-8}$ Porém, são necessários esforços para a identificação, desenvolvimento e implementação de estratégias fortalecedoras de transição que permitam a continuidade do cuidado, especialmente na alta hospitalar no Sistema Único de Saúde (SUS).

A apresentação de análise detalhada e atualizada das estratégias de transição do cuidado, que envolvem enfermeiros na alta hospitalar e retorno ao domicílio, pode aumentar o conhecimento acerca da continuidade do cuidado e estimular seu fortalecimento. Espera-se contribuir para a prática com base em evidências e para a tomada de decisão dos enfermeiros. Assim, o objetivo do estudo consiste em identificar as estratégias de transição do cuidado para a alta hospitalar, utilizadas por enfermeiros para o fortalecimento da continuidade do cuidado, disponíveis na literatura científica.

\section{Método}

Trata-se de revisão integrativa da literatura, elaborada e estruturada a partir de protocolo composto pelas etapas: (1) definição da questão de revisão; (2) amostragem e seleção; (3) representação das características do material captado; (4) análise da amostra selecionada; (5) interpretação dos resultados; e (6) apresentação final. ${ }^{9}$

Na Etapa 1, definiu-se a questão de revisão: quais estratégias de transição do cuidado para a alta hospitalar são utilizadas por enfermeiros para o fortalecimento da continuidade do cuidado, 
Estratégias de transição para alta hospitalar utilizadas por enfermeiros: revisão integrativa | 4 disponíveis na literatura científica? Foi utilizada a estratégia PICO, acrônimo para Paciente (P), Intervenção (I), Comparação (C) e “Outcomes”(desfecho) (O). Pode ser utilizada para questionamentos oriundos da clínica, do gerenciamento de recursos humanos e materiais, da busca de instrumentos para avaliação de sintomas, entre outros. ${ }^{7}$ Assim, foram definidos $\mathrm{P}$ - enfermeiros, I - estratégias de transição, C - não se aplica e O - continuidade do cuidado.

$\mathrm{Na}$ etapa 2, foi obtida a definição da estratégia de busca, iniciada com a escolha das bases de dados Biblioteca Virtual de Saúde (BVS), Cumulative Index to Nursing and Allied Health Literature (CINAHL), U. S. National Library of Medicine (PubMed), SCOPUS e Web of Science (WoS) por duas pesquisadoras, de forma independente. Esta definição foi seguida pela definição da amostragem e seleção, definidas pelo recorte de coleta concernente aos filtros de busca nas bases de dados e período. Foram selecionados descritores controlados obtidos nos Descritores em Ciência da Saúde (DeCS), sendo eles enfermeira, cuidado transicional, continuidade da assistência ao paciente; e no Medical Subject Headings $(\mathrm{MeSH})$, foram selecionados os descritores nurse, care transition, care continuity e continuity of patient. Estes descritores foram combinados com conectores booleanos e representaram as estratégias de busca "care transition" OR "Continuity of Patient Care" OR "care continuity" AND nurse, para as bases de dados BVS, PubMed, SCOPUS e WoS; e "care transition" OR "care continuity" AND nurse para CINAHL. Os estudos recuperados foram exportados para o gerenciador de referências Endnote $W_{e}{ }^{\oplus}$, , com ordenação em pastas para cada base de dados, com posterior identificação e remoção das duplicidades. A coleta de dados ocorreu em agosto de 2020.

Foram adotados como critérios de inclusão artigos completos, nos idiomas inglês, português ou espanhol, publicados entre janeiro de 2016 e agosto de 2020, que apresentassem no título ou resumo as estratégias utilizadas por enfermeiros para fortalecer a continuidade do cuidado entre os serviços de saúde. Os critérios de exclusão foram artigos de revisão.

As estratégias aplicadas permitiram a recuperação de 2.246 artigos nas bases de dados, com posterior remoção de 489 por duplicidade, permanecendo 1.757 para avaliação de títulos e resumos. A aplicação dos critérios de inclusão resultou em 128, que foram lidos na íntegra. A seleção final foi de 
5 | Gallo VCL, Khalaf DKK, Hammerschmidt KSA, Santiago ML, Vendruscolo C

23 artigos, conforme fluxograma (Figura 1).

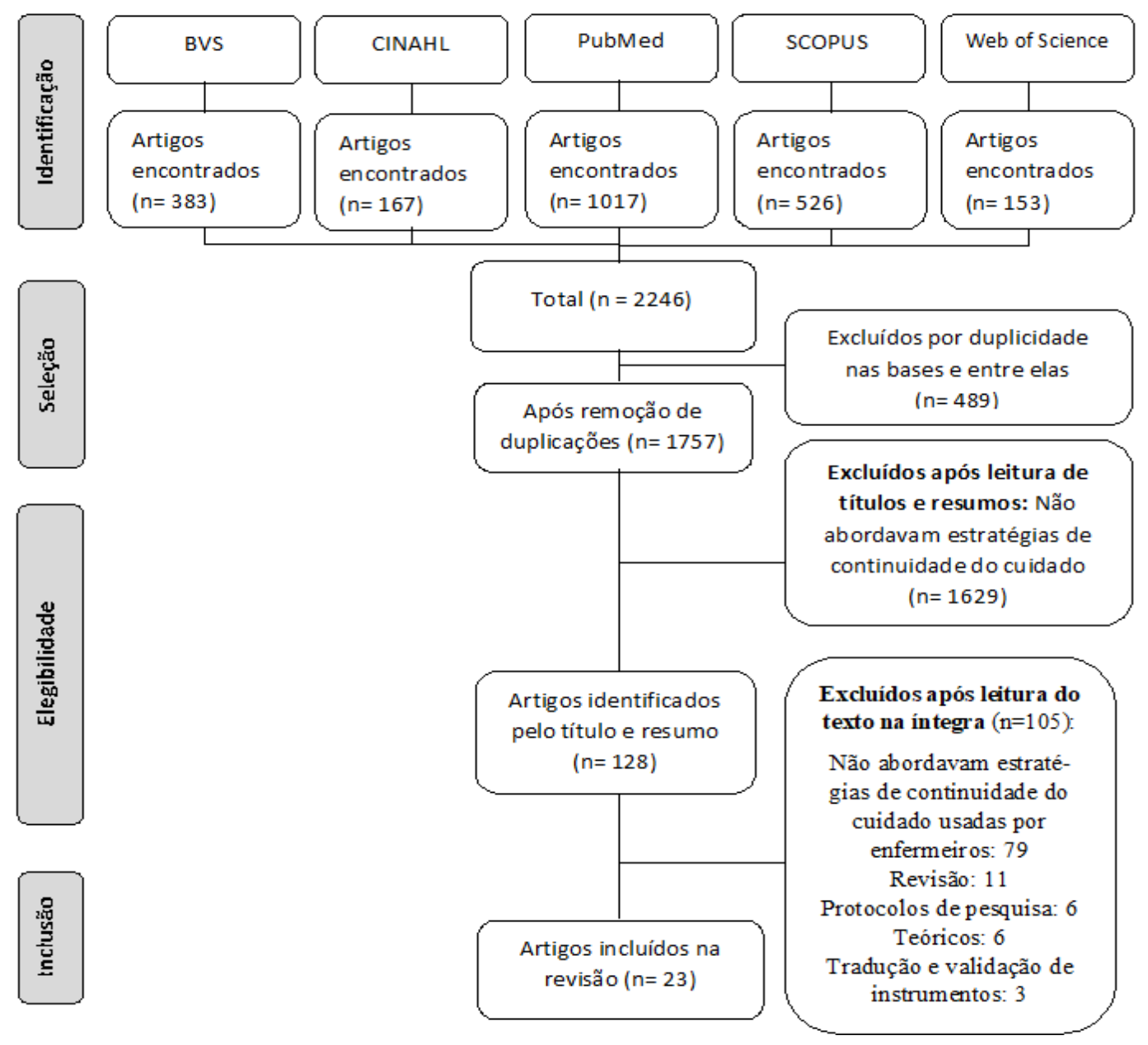

Figura 1- Fluxograma de seleção de estudos primários, 2020.

Nas publicações da amostra (corpus de análise), foram identificados os níveis de evidência (NE) de cada estudo. Os níveis são classificados em NE 1, revisões sistemáticas ou metanálise; NE 2, ensaios clínicos randomizados; NE 3, ensaio clínico controlado não randomizado; NE 4, casos-controle e coorte; NE 5, revisões sistemáticas de estudos descritivos e estudos qualitativos; NE 6, evidência de um único estudo descritivo ou qualitativo; e NE 7, relatórios de opiniões de especialistas. ${ }^{10}$

$\mathrm{Na}$ etapa 3, representação das características do material captado, são apresentadas informações sobre os estudos selecionados para o corpus de análise. O uso de planilha Microsoft Office Excel ${ }^{\circledR}$ permitiu organizar os dados, distribuídos nos campos código de referência, nível de evidência, ano de publicação, título, autores, base de dados, periódico, local do estudo, desenho metodológico, objetivo e estratégia de transição do cuidado após a alta hospitalar. 
Estratégias de transição para alta hospitalar utilizadas por enfermeiros: revisão integrativa |6

Os 23 artigos selecionados para a revisão foram analisados na etapa 4, em três fases (pré-análise, exploração e interpretação), conforme o processo de codificação e análise. Na fase de pré-análise, foi feita a leitura flutuante do material. $\mathrm{Na}$ fase de exploração, as operações de codificação incluíram os recortes das unidades de registro dos resultados dos estudos, a agregação das informações em categorias iniciais a partir da identificação de palavras-chave e a agregação temática com a formação de categorias iniciais, intermediárias e finais. Na terceira fase, ocorreu a interpretação dos conteúdos, ressaltando os aspectos semelhantes e diferentes dos estudos. Contou-se com auxílio de planilhas do Microsoft Office Excel ${ }^{\circledR}$ para o processo de decodificação e codificação com agrupamento por semelhanças.

A análise permitiu identificar as unidades de registro, que foram agrupadas em categorias temáticas iniciais, envolvendo estratégias de transição do cuidado realizado pelos enfermeiros. Na etapa 5, interpretação dos resultados, as categorias iniciais foram articuladas entre si, formando seis categorias intermediárias. A etapa 6 constituiu na apresentação final do artigo, tendo as contribuições dos estudos sido destacadas na primeira vez que aparecem no texto, fazendo menção ao código referência.

\section{Resultados}

Conforme observado no Quadro 1, foram 23 artigos selecionados e analisados: oito $(34,8 \%)$ oriundos da base de dados SCOPUS; sete (30,5\%), da BVS; cinco (21,7\%), da CINAHL; dois (8,7\%), da PubMed; e um (4,3\%), da WoS.

Quadro 1 - Caracterização da amostra da revisão integrativa, 2020.

\begin{tabular}{|c|c|c|c|c|}
\hline $\begin{array}{c}\text { Código de } \\
\text { referência / } \\
\text { Ano de }\end{array}$ & $\begin{array}{c}\text { Desenho } \\
\text { Metodológico } \\
\text { / Nível de } \\
\text { evidência }\end{array}$ & Objetivo & $\begin{array}{c}\text { Estratégia de continuidade do cuidado } \\
\text { após a alta hospitalar }\end{array}$ & Principais resultados \\
Publicação & & & \\
\hline
\end{tabular}




\begin{tabular}{|c|c|c|c|c|}
\hline $\begin{array}{l}1^{11} \\
2016\end{array}$ & $\begin{array}{l}\text { Estudo quase } \\
\text { experimental } \\
\text { NE- } 4\end{array}$ & $\begin{array}{l}\text { Avaliar o efeito da } \\
\text { tele-enfermagem } \\
\text { na adesão aos } \\
\text { planos } \\
\text { tratamento de } \\
\text { pacientes } \quad \text { que } \\
\text { receberam alta } \\
\text { após cirurgia de } \\
\text { revascularização do } \\
\text { miocárdio }\end{array}$ & $\begin{array}{l}\text { Grupo controle: educação de rotina e } \\
\text { preenchimento de questionário de } \\
\text { adesão ao plano de tratamento antes } \\
\text { da alta e cinco semanas após a alta; } \\
\text { Grupo de intervenção: educação de } \\
\text { rotina, seis atendimentos de tele- } \\
\text { enfermagem e questionário de adesão } \\
\text { ao plano de tratamento antes da alta e } \\
\text { na quinta semana. }\end{array}$ & $\begin{array}{l}\text { A tele-enfermagem pode ser } \\
\text { usada como sistema de } \\
\text { prestação de cuidados } \\
\text { continuados de saúde para } \\
\text { aumentar a adesão ao } \\
\text { tratamento, para pacientes } \\
\text { revascularizados. }\end{array}$ \\
\hline $\begin{array}{l}2^{12} \\
2018\end{array}$ & $\begin{array}{l}\text { Estudo pilo } \\
\text { NE- } 4\end{array}$ & $\begin{array}{l}\text { Fornecer apoio aos } \\
\text { pacientes após a } \\
\text { alta até o início do } \\
\text { acompanhamento } \\
\text { pela atenção } \\
\text { primária, para uma } \\
\text { transição tranquila } \\
\text { após a alta. }\end{array}$ & $\begin{array}{l}\text { Reunião de alta, identificação dos } \\
\text { pacientes, discussão das intervenções } \\
\text { planejadas e contato antes da alta para } \\
\text { explicar a intervenção. }\end{array}$ & $\begin{array}{l}\text { A enfermeira de transição } \\
\text { apoiou a transição do hospital } \\
\text { para a atenção primária à } \\
\text { saúde (APS) com resultados } \\
\text { positivos para melhorar a } \\
\text { qualidade do atendimento } \\
\text { para pacientes com maior } \\
\text { risco, como diabéticos e } \\
\text { dependentes químicos. }\end{array}$ \\
\hline $\begin{array}{l}3^{13} \\
2016\end{array}$ & $\begin{array}{l}\text { Ensaio clínico } \\
\text { randomizado } \\
\mathrm{NE}-2\end{array}$ & $\begin{array}{l}\text { Avaliar a eficácia } \\
\text { de uma intervenção } \\
\text { de transição de } \\
\text { cuidados, usando } \\
\text { monitoramento } \\
\text { remoto } \\
\text { pacientes } \\
\text { redução ne } \\
\text { readmissões nor } \\
\text { todas as causas em } \\
\begin{array}{lr}\text { 180 dias em uma } \\
\text { população }\end{array} \\
\text { idosos de } \\
\text { insuficiência } \\
\text { cardíaca. }\end{array}$ & $\begin{array}{l}\text { Educação pré-alta (cartilha, orientação } \\
\text { do uso do midia play portátil, balança } \\
\text { e monitor de pressão arterial e } \\
\text { frequência cardíaca); } \\
\text { Nove ligações telefônicas de } \\
\text { treinamento, reforçando as } \\
\text { orientações pré-alta (entre } 48 \text { e } 72 \\
\text { horas após a alta; segunda semana; } \\
\text { entre terceira e quarta semana; } \\
\text { mensalmente até seis meses) } \\
\text { Telemonitoramento por mensagem ao } \\
\text { call center sobre o peso, pressão } \\
\text { arterial e frequência cardíaca e três } \\
\text { sintomas. }\end{array}$ & $\begin{array}{l}\text { A intervenção teve efeito } \\
\text { significativo na melhora da } \\
\text { qualidade de vida entre os } \\
\text { respondentes em } 180 \text { dias. }\end{array}$ \\
\hline $\begin{array}{l}4^{14} \\
2018\end{array}$ & $\begin{array}{l}\text { Estudo piloto } \\
\text { NE- } 4\end{array}$ & $\begin{array}{l}\text { Criar um modelo } \\
\text { de atendimento } \\
\text { Care Transsition } \\
\text { Intervention-CTI. }\end{array}$ & $\begin{array}{l}\text { Contato telefônico estruturado até } 18 \\
\text { horas após a alta hospitalar, com o uso } \\
\text { de roteiro abordando a compreensão } \\
\text { da doença, manutenção da saúde e } \\
\text { autocuidado. }\end{array}$ & $\begin{array}{l}\text { Consultas telefônicas } \\
\text { estruturadas para revisar } \\
\text { orientações de autocuidado e } \\
\text { manutenção e promoção da } \\
\text { saúde são intervenções } \\
\text { simples e eficazes para } \\
\text { reduzir as taxas de } \\
\text { readmissão em } 30 \text { dias após a } \\
\text { alta. }\end{array}$ \\
\hline $\begin{array}{l}5^{15} \\
2019\end{array}$ & $\begin{array}{l}\text { Estudo piloto } \\
\text { NE- } 4\end{array}$ & $\begin{array}{l}\text { Implementar um } \\
\text { processo } \\
\text { consistente de }\end{array}$ & $\begin{array}{l}\text { Conferência de listas de pacientes } \\
\text { com diagnóstico de insuficiência } \\
\text { cardíaca com alta hospitalar; }\end{array}$ & $\begin{array}{l}\text { Programas de chamada pós- } \\
\text { alta são uma forma simples e } \\
\text { eficaz de identificar e intervir }\end{array}$ \\
\hline
\end{tabular}




\begin{tabular}{|c|c|c|c|c|}
\hline & & $\begin{array}{l}\text { chamadas } \\
\text { telefônicas de } 48 \\
\text { horas pós-alta para } \\
\text { pacientes com } \\
\text { insuficiência } \\
\text { cardíaca (IC). }\end{array}$ & $\begin{array}{l}\text { Ligação telefônica, } 48 \text { horas após a } \\
\text { alta, com o uso de script desenvolvido } \\
\text { pelo serviço e registrado no } \\
\text { prontuário eletrônico compartilhado } \\
\text { com o provedor da atenção primária. }\end{array}$ & $\begin{array}{l}\text { nos problemas dos pacientes } \\
\text { após a alta. Os enfermeiros } \\
\text { desempenham papel } \\
\text { fundamental em programas } \\
\text { de monitoramento pós-alta } \\
\text { para transição de cuidado } \\
\text { segura. }\end{array}$ \\
\hline $\begin{array}{l}6^{16} \\
2016\end{array}$ & $\begin{array}{l}\text { Estudo de } \\
\text { caso controle } \\
\mathrm{NE}-4\end{array}$ & $\begin{array}{l}\text { Reduzir as taxas de } \\
\text { readmissão pós- } \\
\text { alta de pacientes } \\
\text { com alto risco de } \\
\text { readmissão. }\end{array}$ & $\begin{array}{l}\text { Aplicação da escala LACE (avaliação } \\
\text { preditora de risco de readmissão ou } \\
\text { morte em } 30 \text { dias) para pacientes } \\
\text { internados em unidades cirúrgicas, } \\
\text { médicas e de telemetria (escore LACE } \\
\text { entre } 11 \text { e } 15 \text { - encaminhados para o } \\
\text { programa por meio de prontuário } \\
\text { eletrônico); } \\
\text { Visita domiciliar única, estruturada } \\
\text { entre } 48 \text { e } 72 \text { horas após a alta para } \\
\text { reconciliação medicamentosa, gestão } \\
\text { e educação de doenças, e } \\
\text { encaminhamento de recursos } \\
\text { contínuos de apoio e ajuste de plano } \\
\text { de cuidados. }\end{array}$ & $\begin{array}{l}\text { Taxa de readmissão em } 30 \\
\text { dias para o grupo controle foi } \\
\text { de } 23,61 \% \text { e no grupo de } \\
\text { intervenção foi de } 12,22 \% \text {. A } \\
\text { associação da avaliação do } \\
\text { escore LACE com visitas } \\
\text { domiciliares estruturadas } \\
\text { reduziu substancialmente as } \\
\text { readmissões em } 30 \text { dias. A } \\
\text { intervenção com visita } \\
\text { domiciliar promoveu maior } \\
\text { comunicação com a equipe de } \\
\text { APS }\end{array}$ \\
\hline $\begin{array}{l}7^{17} \\
2018\end{array}$ & $\begin{array}{l}\text { Ensaio clínico } \\
\text { randomizado } \\
\mathrm{NE}-2\end{array}$ & $\begin{array}{l}\text { Avaliar se uma } \\
\text { ligação telefônica } \\
\text { programada, } \\
\text { realizada por uma } \\
\text { enfermeira de um } \\
\text { hospital diminui a } \\
\text { taxa de retorno ao } \\
\text { pronto-socorro, } \\
\text { reinternação ou } \\
\text { morte, em } 30 \text { dias }\end{array}$ & $\begin{array}{l}\text { Telefonema de uma enfermeira } 1 \text { a } 3 \\
\text { dias após a alta, usando um } \\
\text { questionário (obstáculos aos } \\
\text { elementos de transições de cuidados } \\
\text { bem-sucedidas: aquisição de } \\
\text { medicamentos, instruções pós-alta e } \\
\text { obtenção de acompanhamento } \\
\text { médico). }\end{array}$ & $\begin{array}{l}\text { Taxa de readmissão em } 30 \\
\text { dias foi de } 15,5 \% \text { no grupo de } \\
\text { intervenção e de } 15,2 \% \text { no } \\
\text { grupo controle. Morte em } 30 \\
\text { dias foi incomum. } \\
\text { Acompanhamento telefônicas } \\
\text { chamadas de } \\
\text { programadas por enfermeiras } \\
\text { após a alta não reduziu as } \\
\text { taxas de retorno em } 30 \text { dias }\end{array}$ \\
\hline $\begin{array}{l}8^{18} \\
2017\end{array}$ & $\begin{array}{l}\text { Estudo pré e } \\
\text { pós- } \\
\text { intervenção } \\
\text { NE- } 4\end{array}$ & $\begin{array}{lr}\text { Avaliar as taxas } & \text { de } \\
\text { readmissão em } & 30 \\
\text { dias, após } & \text { a } \\
\text { implementação } & \text { de } \\
\text { um programa } & \text { de } \\
\text { serviço } & \text { de } \\
\text { transição } & \text { de } \\
\text { cuidados. }\end{array}$ & $\begin{array}{l}\text { Abordagem multifacetada: } \\
\text { identificação das taxas de readmissão } \\
\text { antes da intervenção; identificação de } \\
\text { pacientes para a intervenção, com } \\
\text { escore de risco (idade, diagnóstico e } \\
\text { hospitalização anterior); planejamento } \\
\text { pré-alta; visita domiciliar, seguida de } \\
\text { três ligações telefônicas (30 dias), } \\
\text { incluindo reconciliação } \\
\text { medicamentosa; e abordagem de } \\
\text { desafios psicossociais. }\end{array}$ & $\begin{array}{l}\text { Taxa de readmissão antes da } \\
\text { intervenção foi de } 13,7 \% \text { e } \\
\text { após, de } 11,4 \% \text {. Envolvimento } \\
\text { da enfermagem no programa } \\
\text { de transição de cuidados é } \\
\text { componente essencial para } \\
\text { identificar pacientes em risco. } \\
\text { Taxas de readmissão } \\
\text { diminuíram significamente } \\
\text { após a intervenção. }\end{array}$ \\
\hline $\begin{array}{l}9^{19} \\
2019\end{array}$ & $\begin{array}{l}\text { Estudo piloto } \\
\text { NE- } 4\end{array}$ & 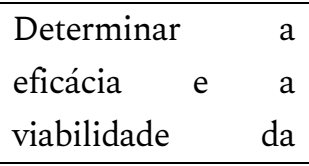 & $\begin{array}{l}\text { Videoconferências agendadas no dia } \\
\text { anterior à alta hospitalar, com a } \\
\text { participação da enfermeira gerente de }\end{array}$ & $\begin{array}{l}\text { Videoconferências } \\
\text { melhoraram a comunicação, } \\
\text { a coordenação do }\end{array}$ \\
\hline
\end{tabular}




\begin{tabular}{|c|c|c|c|c|}
\hline & & $\begin{array}{l}\text { transferência por } \\
\text { videoconferência } \\
\text { de atendimento } \\
\text { hospitalar para o } \\
\text { domicílio em } \\
\text { pediatria. }\end{array}$ & $\begin{array}{l}\text { caso, de cabeceira, da APS, paciente e } \\
\text { família. } \\
\text { Usar um tablet com aplicativo seguro } \\
\text { de videoconferência e uma lista de } \\
\text { verificação. Discussão do caso } \\
\text { abordando o estado de saúde, } \\
\text { segurança, intervenções, resposta ao } \\
\text { tratamento, plano de cuidados e } \\
\text { necessidade de equipamentos, } \\
\text { suprimentos e visitas. }\end{array}$ & $\begin{array}{l}\text { atendimento e } \\
\text { envolvimento da equipe } \\
\text { durante a transição do } \\
\text { cuidado e têm potencial de } \\
\text { diminuir a ansiedade, ao } \\
\text { melhorar a preparação, bem } \\
\text { como aumentar o conforto } \\
\text { com a chegada de uma } \\
\text { enfermeira à sua casa. A } \\
\text { videoconferência pode ser um } \\
\text { meio viável e eficaz de atingir } \\
\text { uma transição suave e } \\
\text { continuidade do cuidado. }\end{array}$ \\
\hline 2019 & $\begin{array}{l}\text { Estudo quase } \\
\text { experimental } \\
\mathrm{NE}-4\end{array}$ & $\begin{array}{l}\text { Avaliar a eficácia } \\
\text { da intervenção de } \\
\text { transição de } \\
\text { múltiplos } \\
\text { componentes } \\
\text { baseada no modelo } \\
\text { ideal de transição } \\
\text { do cuidado (ITC), } \\
\text { na redução da } \\
\text { readmissão em } 30 \text { e } \\
90 \text { dias. }\end{array}$ & $\begin{array}{l}\text { Seleção dos pacientes, envolvimento } \\
\text { precoce para antecipar as } \\
\text { necessidades da alta; reconciliação } \\
\text { medicamentosa; educação do } \\
\text { paciente; orientações antecipadas e } \\
\text { plano de contingência; e } \\
\text { acompanhamento com ligação } \\
\text { estruturada (avaliar sintomas e revisão } \\
\text { de orientações). }\end{array}$ & $\begin{array}{l}\text { Pacientes tiveram chances } \\
\text { menores de readmissão em } 30 \\
\text { e } 90 \text { dias. Intervenção de } \\
\text { múltiplos fatores realizada } \\
\text { por enfermeiros foi eficaz } \\
\text { para a redução de readmissão } \\
\text { em } 30 \text { e } 90 \text { dias e para a } \\
\text { redução de custos. }\end{array}$ \\
\hline $\begin{array}{l}11^{21} \\
2018\end{array}$ & $\begin{array}{l}\text { Estudo piloto } \\
\text { NE- } 4\end{array}$ & $\begin{array}{lr}\text { Implantar } & \text { o } \\
\text { programa } & \text { de } \\
\text { cuidados } & \text { de } \\
\text { transição } & \\
\text { denominado } \\
\text { Transitions Across } \\
\text { Care Settings - } \\
\text { TRACS. }\end{array}$ & $\begin{array}{l}\text { Visita domiciliar com avaliação da } \\
\text { necessidade de educação, avaliação } \\
\text { ambiental, educação personalizada } \\
\text { para autogestão de cuidados em casa, } \\
\text { com conciliação medicamentosa } \\
\text { (fornecimento de caixa de } \\
\text { medicamento). } \\
\text { Ligação telefônica semanal para } \\
\text { monitoramento e reforço de } \\
\text { orientações. } \\
\text { Comunicação da APS sobre o estado } \\
\text { de saúde e necessidades de } \\
\text { acompanhamento, com o auxílio de } \\
\text { formulários de comunicação. }\end{array}$ & $\begin{array}{l}\text { Melhoria da comunicação } \\
\text { entre os serviços de saúde, } \\
\text { autogestão e autocuidado. }\end{array}$ \\
\hline $\begin{array}{l}12^{22} \\
2016\end{array}$ & $\begin{array}{l}\text { Ensaio clínico } \\
\text { randomizado } \\
\mathrm{NE}-2\end{array}$ & $\begin{array}{l}\text { Avaliar o impacto } \\
\text { do programa } E- \\
\text { Coach nas taxas de } \\
\text { readmissão, ou } \\
\text { morte após a alta } \\
\text { em pacientes com } \\
\text { doença pulmonar } \\
\text { crônica obstrutiva }\end{array}$ & $\begin{array}{l}\text { E-Coach é intervenção com } \\
\text { customização específica para a } \\
\text { condição e apoio intra-hospitalar e } \\
\text { pós-alta por uma enfermeira de } \\
\text { transição de cuidados, chamadas de } \\
\text { resposta de voz interativa pós-alta e } \\
\text { acompanhamento de enfermagem } \\
\text { versus cuidados pós-alta usuais. }\end{array}$ & $\begin{array}{l}\text { Taxa geral de reinternação } \\
\text { para o grupo controle foi de } \\
16,3 \% \text { e do grupo de } \\
\text { intervenção, de } 15,0 \% \text { O } \\
\text { sistema coletou os dados do } \\
\text { paciente, forneceu educação e } \\
\text { motivação personalizadas e } \\
\text { alertou o enfermeiro quanto }\end{array}$ \\
\hline
\end{tabular}




\begin{tabular}{|c|c|c|c|c|}
\hline & & (DPOC) e IC. & $\begin{array}{l}\text { Durante internação: avaliação e } \\
\text { treinamento pelo enfermeiro de } \\
\text { transição de cuidados em relação à } \\
\text { autogestão de medicamentos, } \\
\text { reconhecimento de sinais e sintomas e } \\
\text { uso do sistema de suporte e } \\
\text { monitoramento E-Coach. } \\
\text { Chamadas automáticas diariamente } \\
\text { por sete dias e após, a cada três dias } \\
\text { até completar } 28 \text { ligações. }\end{array}$ & às respostas de alerta. \\
\hline $\begin{array}{l}13^{23} \\
2019\end{array}$ & $\begin{array}{l}\text { Ensaio clínico } \\
\text { randomizado } \\
\text { multicêntrico } \\
\text { NE- } 2\end{array}$ & 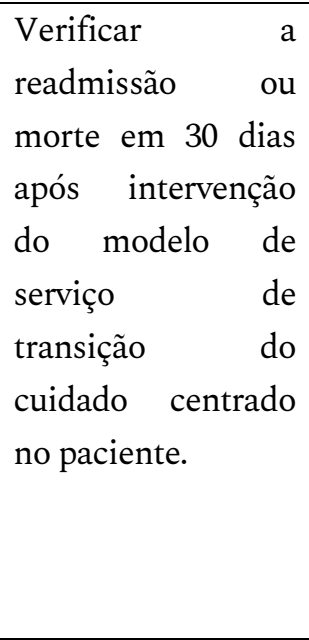 & $\begin{array}{l}\text { Grupo de cuidados habituais: } \\
\text { educação e uma visita domiciliar } \\
\text { Intervenção: enfermeira no momento } \\
\text { da alta avaliou as necessidades, } \\
\text { forneceu educação para o autocuidado } \\
\text { com resumo de alta estruturado, } \\
\text { arranjos para acompanhamento } \\
\text { médico na APS, encaminhamento } \\
\text { para visita domiciliar pós-alta por } \\
\text { enfermeiras, seguida de visitas } \\
\text { semanais estruturadas ou ligações } \\
\text { telefônicas por quatro a seis semanas. }\end{array}$ & $\begin{array}{l}\text { Taxas de readmissão em três } \\
\text { meses foram de } 49,4 \% \text { para o } \\
\text { grupo de intervenção e de } \\
50,2 \% \text { para o grupo controle, } \\
\text { sem diferença significativa. }\end{array}$ \\
\hline $\begin{array}{l}14^{24} \\
2017\end{array}$ & $\begin{array}{l}\text { Estudo } \\
\text { descritivo } \\
\text { NE- } 6\end{array}$ & $\begin{array}{l}\text { Identificar } \\
\text { quantificar as } \\
\text { atividades } \\
\text { enfermeira } \\
\text { navegadora para a } \\
\text { coordenação da } \\
\text { alta hospitalar. }\end{array}$ & $\begin{array}{l}\text { Acompanhamento do paciente com } \\
\text { ajuda para o paciente, com ligações } \\
\text { para orientação ou retransmissão de } \\
\text { informações; } \\
\text { Gerenciamento de problemas } \\
\text { técnicos, com ligações para alertar } \\
\text { sobre disfunções de atendimento } \\
\text { como entrega de insumos, } \\
\text { equipamentos com mau } \\
\text { funcionamento; e orientação de } \\
\text { protocolos de atendimento com } \\
\text { esclarecimentos. }\end{array}$ & $\begin{array}{l}\text { As atividades das enfermeiras } \\
\text { envolvem a coordenação } \\
\text { organizacional e gerencial, } \\
\text { treinamento e qualificação } \\
\text { para pacientes e profissionais. } \\
\text { Possibilidade de coleta e } \\
\text { transmissão de dados do } \\
\text { paciente para outros serviços. }\end{array}$ \\
\hline $\begin{array}{l}15^{25} \\
2016\end{array}$ & $\begin{array}{l}\text { Estudo piloto } \\
\text { NE- } 4\end{array}$ & $\begin{array}{l}\text { Avaliar se uma lista } \\
\text { de verificação de } \\
\text { educação pós- } \\
\text { operatória reduz as } \\
\text { readmissões entre } \\
\text { novos } \\
\text { ileostomizados }\end{array}$ & $\begin{array}{l}\text { Elaboração de lista de verificação de } \\
\text { conhecimento centrada no paciente, } \\
\text { com habilidades consideradas } \\
\text { essenciais para o sucesso da alta com } \\
\text { ileostomia ( } 24 \text { horas após a cirurgia, } \\
\text { com orientações durante a } \\
\text { internação). } \\
\text { Acompanhamento da autonomia do } \\
\text { paciente. }\end{array}$ & $\begin{array}{l}\text { Redução significativa na } \\
\text { readmissão atribuída à lista } \\
\text { de verificação }(\mathrm{P}=0,04) \text {. Lista } \\
\text { de verificação centrada no } \\
\text { paciente e orientada para o } \\
\text { autocuidado, concentrada na } \\
\text { autonomia na } \\
\text { independência; melhora } \\
\text { significativamente da taxa de } \\
\text { readmissão após confecção de } \\
\text { ileostomia. }\end{array}$ \\
\hline $16^{26}$ & Estudo pré e & Reduzir visitas ao & Alerta de transição de cuidados com & Uso da ciência de dados pode \\
\hline
\end{tabular}




\begin{tabular}{|c|c|c|c|c|}
\hline 2018 & $\begin{array}{l}\text { pós- } \\
\text { intervenção } \\
\text { NE- } 4\end{array}$ & 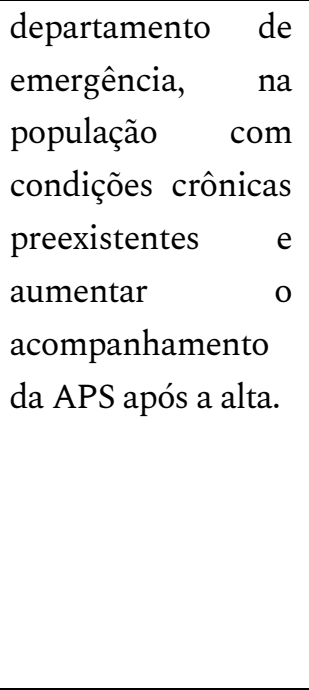 & $\begin{array}{l}\text { troca de informações de saúde até } 24 \\
\text { horas, por mensagem eletrônica } \\
\text { segura, com consentimento do } \\
\text { paciente, de forma automatizada. } \\
\text { Uso do software ePECAM como } \\
\text { suporte à decisão clínica, preenchido } \\
\text { pelo enfermeiro na ligação telefônica. } \\
\text { Algoritmo clínico COMPLEXedex, } \\
\text { com análise de Big Data (dados do } \\
\text { prontuário eletrônico estratificam o } \\
\text { risco de reinternação com bases nas } \\
\text { comorbidades). }\end{array}$ & $\begin{array}{l}\text { harmonizar o cuidado } \\
\text { centrado na pessoa, com } \\
\text { práticas de cuidados de } \\
\text { transição, baseadas em } \\
\text { evidências, o que qualifica os } \\
\text { cuidados de enfermagem. } \\
\text { Incorporar informações sobre } \\
\text { os determinantes sociais e } \\
\text { comportamentais de saúde no } \\
\text { prontuário eletrônico para } \\
\text { intercâmbio entre os serviços. } \\
\text { Estratificação de risco de } \\
\text { reinternação do paciente. }\end{array}$ \\
\hline $\begin{array}{l}17^{27} \\
2016\end{array}$ & $\begin{array}{l}\text { Estudo } \\
\text { descritivo } \\
\text { retrospectivo } \\
\text { NE- } 6\end{array}$ & 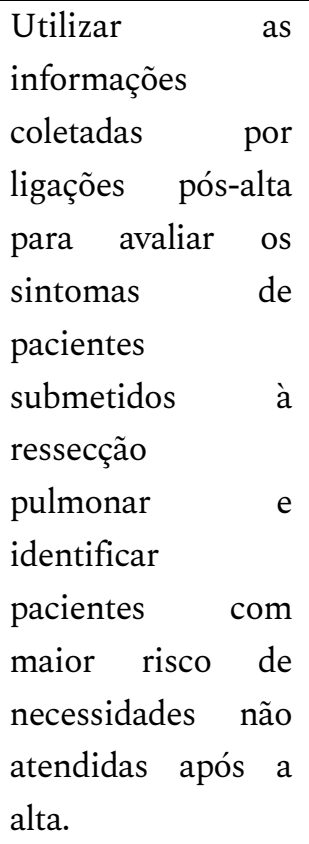 & $\begin{array}{l}\text { Contato telefônico realizado por } \\
\text { enfermeiras (perguntas roteirizadas na } \\
\text { primeira semana após a alta hospitalar } \\
\text { para avaliar as condições de saúde e } \\
\text { fornecer aconselhamento de saúde). } \\
\text { Registro do atendimento no } \\
\text { prontuário eletrônico } \\
\text { encaminhamento para serviços em } \\
\text { casos de necessidade. }\end{array}$ & $\begin{array}{l}\text { Dos } 523 \text { pacientes submetidos } \\
\text { à ressecção pulmonar, } 245 \\
(46,8 \%) \text { receberam contato } \\
\text { telefônico, em média, de } 4,6 \\
\text { dias após a alta e } 81(33,1 \%) \\
\text { necessitaram de } \\
\text { aconselhamento durante as } \\
\text { ligações. Pacientes com riscos } \\
\text { de ter dificuldades de } \\
\text { cuidados após a alta. } \\
\text { Tentativas de preparar } \\
\text { melhor os pacientes para a } \\
\text { alta. }\end{array}$ \\
\hline $\begin{array}{l}18^{28} \\
2019\end{array}$ & $\begin{array}{l}\text { Estudo } \\
\text { descritivo } \\
\text { quantitativo } \\
\text { NE- } 6\end{array}$ & $\begin{array}{lr}\text { Identificar } & \text { e } \\
\text { descrever } & \text { as } \\
\text { atividades } & \text { da } \\
\text { enfermeira } & \text { de } \\
\text { ligação para } & \text { a } \\
\text { continuidade do } & \text { duidado após a alta } \\
\text { cuspitalar. }\end{array}$ & $\begin{array}{l}\text { Seleção de pacientes por busca ativa } \\
\text { ou indicação da equipe } \\
\text { multiprofissional. } \\
\text { Planejamento da alta hospitalar } \\
\text { iniciado em diferentes momentos da } \\
\text { internação (entrevistas com pacientes } \\
\text { e familiares). } \\
\text { Enfermeiras de ligação fazem a } \\
\text { transferência de informações entre o } \\
\text { hospital e outros serviços com apoio } \\
\text { de tecnologias de informação e } \\
\text { comunicação (TIC) entre } 48 \text { horas } \\
\text { antes da alta e } 24 \text { horas após a alta. }\end{array}$ & $\begin{array}{l}\text { Enfermeira de ligação atua } \\
\text { como coordenadora do } \\
\text { processo de alta e participa } \\
\text { ativamente da identificação } \\
\text { das necessidades de cuidados } \\
\text { após a alta. Contribuição para } \\
\text { a continuidade do cuidado } \\
\text { com identificação das } \\
\text { condições clínicas e sociais, } \\
\text { levantamento das } \\
\text { necessidades e recursos na } \\
\text { APS, e reforço nas } \\
\text { orientações para a alta. }\end{array}$ \\
\hline
\end{tabular}




\begin{tabular}{|c|c|c|c|c|}
\hline $\begin{array}{l}19^{29} \\
2018\end{array}$ & $\begin{array}{l}\text { Ensaio clínico } \\
\text { randomizado } \\
\mathrm{NE}-2\end{array}$ & $\begin{array}{l}\text { Determinar se uma } \\
\text { única ligação } \\
\text { telefônica } \\
\text { conduzida por } \\
\text { enfermeiro após a } \\
\text { alta diminui a taxa } \\
\text { de reutilização do } \\
\text { serviço hospitalar. }\end{array}$ & $\begin{array}{l}\text { Chamada telefônica entre } 48 \text { e } 96 \\
\text { horas após a alta, com apoio de } \\
\text { modelo padronizado para a doença, } \\
\text { usado em visitas domiciliares. } \\
\text { Orientações de reforço de instruções } \\
\text { de alta. } \\
\text { Identificação de alterações, contato } \\
\text { com o médico clínico ou da APS para } \\
\text { controle e cuidados padronizados de } \\
\text { educação para a alta. }\end{array}$ & $\begin{array}{l}442(91,5 \%) \text { receberam } \\
\text { ligações em até } 96 \text { horas. Taxa } \\
\text { de reutilização do hospital em } \\
30 \text { dias no grupo controle foi } \\
\text { de } 13,1 \% \text { e no grupo } \\
\text { intervenção, de } 15,9 \% \text {. Única } \\
\text { ligação telefônica conduzida } \\
\text { por enfermeiro não alterou a } \\
\text { taxa de reutilização do serviço } \\
\text { de saúde. Intervenção foi bem } \\
\text { aceita após a alta, e os pais } \\
\text { foram mais capazes de } \\
\text { identificar sinais de alerta na } \\
\text { criança. }\end{array}$ \\
\hline & $\begin{array}{l}\text { Ensaio clínico } \\
\text { randomizado } \\
\mathrm{NE}-2\end{array}$ & $\begin{array}{l}\text { Examinar a eficácia } \\
\text { de uma intervenção } \\
\text { der suporte } \\
\text { telefônico baseada } \\
\text { em cuidados } \\
\text { primários para } \\
\text { veteranos após alta } \\
\text { do departamento } \\
\text { de emergência. }\end{array}$ & $\begin{array}{l}\text { Cuidados de atendimento usual de } \\
\text { enfermagem, incluindo recomendação } \\
\text { para agendamento de atendimento } \\
\text { coma APS. } \\
\text { Duas chamadas telefônicas } \\
\text { estruturadas com foco em melhorar a } \\
\text { transição do departamento de } \\
\text { emergência para a APS, } \\
\text { autogerenciamento de doenças } \\
\text { crônicas e educação sobre o modelo } \\
\text { de APS (possibilidade de uma } \\
\text { chamada adicional). }\end{array}$ & $\begin{array}{l}\text { Taxa de retorno em } 30 \text { dias ao } \\
\text { departamento de emergência } \\
\text { foi de } 23,1 \% \text { e de } 24,9 \% \text { para o } \\
\text { grupo de controle e } \\
\text { intervenção, respectivamente. } \\
\text { Programa de apoio por } \\
\text { telefone liderado por } \\
\text { enfermeiras após } \\
\text { atendimento ao pronto- } \\
\text { socorro não diminuiu as } \\
\text { visitas repetidas ao hospital. } \\
\text { Programas devem concentrar } \\
\text { fatores sociopsicológicos para } \\
\text { atender as necessidades de } \\
\text { saúde. }\end{array}$ \\
\hline $\begin{array}{l}21^{31} \\
2017\end{array}$ & $\begin{array}{l}\text { Estudo } \\
\text { prospectivo } \\
\text { NE- } 6\end{array}$ & $\begin{array}{l}\text { Reduzir as taxas de } \\
\text { reinternação em } 30 \\
\text { dias de pacientes } \\
\text { com insuficiência } \\
\text { cardíaca (IC). }\end{array}$ & $\begin{array}{l}\text { Programa } S T O P \text {-HF-Clinic: uma } \\
\text { visita precoce na primeira semana de } \\
\text { alta por uma enfermeira; avaliação } \\
\text { para identificar alteração (potencial } \\
\text { para descompensação) e solicitação de } \\
\text { avaliações complementares; coleta de } \\
\text { sangue para análise laboratorial; } \\
\text { atividades de educação personalizada } \\
\text { em saúde para o paciente e cuidador; } \\
\text { três novas visitas para ajuste e } \\
\text { orientações (durante os } 30 \text { dias); } \\
\text { administração de medicação; envio de } \\
\text { mensagem eletrônica ao paciente } \\
\text { (após } 30 \text { dias) e registro no prontuário } \\
\text { eletrônico }\end{array}$ & $\begin{array}{l}\text { Média de tempo entre a alta e } \\
\text { a primeira visita foi de } 5 \text { dias; } \\
\text { o número médio de visitas } \\
\text { pós-alta foi de 3,1 dias. Taxa } \\
\text { de reinternação por qualquer } \\
\text { causa em } 30 \text { dias foi reduzida } \\
\text { em } 47,5 \% \text { com a intervenção. } \\
\text { Enfermeiras foram } \\
\text { responsáveis pela conciliação } \\
\text { medicamentosa, educação em } \\
\text { saúde para o autocuidado e } \\
\text { participação no tratamento } \\
\text { imediato de alterações. } 518 \\
\text { pacientes foram orientados e } \\
\text { acompanhados. }\end{array}$ \\
\hline $\begin{array}{l}22^{32} \\
2018\end{array}$ & $\begin{array}{l}\text { Pesquisa de } \\
\text { intervenção }\end{array}$ & $\begin{array}{lr}\text { Identificar } & \text { o perfil } \\
\text { dos } & \text { usuários }\end{array}$ & $\begin{array}{l}\text { Seleção do usuário e suas necessidades } \\
\text { de cuidado após a alta hospitalar; }\end{array}$ & $\begin{array}{lcr}43 & \text { usuários } & \text { foram } \\
\text { contrarreferenciados } & \text { para a }\end{array}$ \\
\hline
\end{tabular}




\begin{tabular}{|c|c|c|c|c|}
\hline & NE- 4 & $\begin{array}{l}\text { contrarreferenciad } \\
\text { os pela enfermeira } \\
\text { de ligação. }\end{array}$ & $\begin{array}{l}\text { Identificação da unidade de saúde da } \\
\text { APS (referência), fazer contato } \\
\text { telefônico com a enfermeira para } \\
\text { discutir as necessidades e agendar } \\
\text { consulta pós-alta; } \\
\text { Preencher formulário de } \\
\text { contrarreferência e enviar junto ao } \\
\text { resumo de alta para a APS (por e-mail, } \\
\text { e entregar uma via para o usuário); } \\
\text { Orientar o usuário a entregar o } \\
\text { formulário para a enfermeira da } \\
\text { unidade de saúde }\end{array}$ & $\begin{array}{l}\text { APS com resumo de alta. } \\
\text { Diálogo entre os serviços de } \\
\text { saúde e a agilidade em } \\
\text { aquisição de insumos para } \\
\text { garantir a continuidade do } \\
\text { cuidado. Enfermeira de } \\
\text { ligação mostrou ser estratégia } \\
\text { para melhorar a integração } \\
\text { entre os serviços e promover a } \\
\text { continuidade do cuidado. }\end{array}$ \\
\hline $\begin{array}{l}23^{33} \\
2017\end{array}$ & $\begin{array}{l}\text { Estudo piloto } \\
\text { NE- } 4\end{array}$ & $\begin{array}{l}\text { Avaliar a } \\
\text { viabilidade e a } \\
\text { utilidade das visitas } \\
\text { domiciliares. pós- } \\
\text { alta para crianças } \\
\text { com } \\
\text { complexidades } \\
\text { médicas. }\end{array}$ & $\begin{array}{l}\text { Visita domiciliar conduzida por } \\
\text { enfermeira ( } 72 \text { a } 96 \text { horas após a alta, } \\
\text { com duração entre } 60-90 \text { minutos). } \\
\text { Temas abordados durante a visita: } \\
\text { reforço na educação sobre o plano de } \\
\text { alta, revisão da lista de medicação, } \\
\text { inspeção e orientação sobre } \\
\text { equipamentos e suprimentos de } \\
\text { cuidados domiciliares, avaliação do } \\
\text { ambiente domiciliar, identificação e } \\
\text { resolução de questões surgidas no } \\
\text { pós-alta e avaliação de determinantes } \\
\text { sociais de saúde. }\end{array}$ & $\begin{array}{l}38 \text { pacientes foram elegíveis } \\
\text { para as visitas, sendo que } 36 \\
(94,7 \%) \text { receberam a visita. } \\
\text { Visitas ocorreram numa } \\
\text { mediana de três dias após a } \\
\text { alta hospitalar e durou em } \\
\text { média } 73 \text { minutos. As visitas } \\
\text { domiciliares ajudaram a } \\
\text { identificar e a resolver } \\
\text { problemas pós-alta que } \\
\text { ocorreram com crianças com } \\
\text { complexidade médica, bem } \\
\text { como avaliação dos } \\
\text { determinantes sociais de } \\
\text { saúde, ambiente domiciliar e } \\
\text { possibilitaram orientações em } \\
\text { saúde. }\end{array}$ \\
\hline
\end{tabular}

Dez (43,5\%) artigos foram publicados em periódicos interprofissionais; oito (34,8\%) de enfermagem e cinco $(21,7 \%)$ de medicina. Os idiomas de publicação foram inglês (86,9\%), português $(8,7 \%)$ e espanhol (4,4\%). Os países de desenvolvimento das pesquisas foram EUA (73,9\%), Canadá $(8,7 \%)$, Irã (4,3\%), França (4,3\%), Espanha (4,3\%) e Brasil (4,3\%).

Quanto ao ano de publicação, seis (26,1\%) foram disponibilizados em 2016, quatro (17,4\%) em 2017, sete (30,4\%) em 2018, cinco (21,7\%) em 2019 e um (4,4\%) em 2020. No que se refere ao delineamento, constatou-se que sete $(30,4 \%)$ foram estudos piloto; seis $(26,1 \%)$, ensaios clínicos randomizados; quatro (17,4\%), estudos descritivos; três, pré e pós-intervenção $(13,1 \%)$; dois $(8,7 \%)$, quase experimentais; e um 
Estratégias de transição para alta hospitalar utilizadas por enfermeiros: revisão integrativa | 14 $(4,3 \%)$ foi caso controle.

Em relação às categorias emergentes, destacam-se as intermediárias: I) educação em saúde, II) reconciliação medicamentosa, III) telemonitoramento, IV) planejamento de alta, V) contrarreferência e VI) visita domiciliar, que conduziram a uma categoria final, desfecho, estratégias de transição do cuidado para a alta hospitalar (Figura 2).

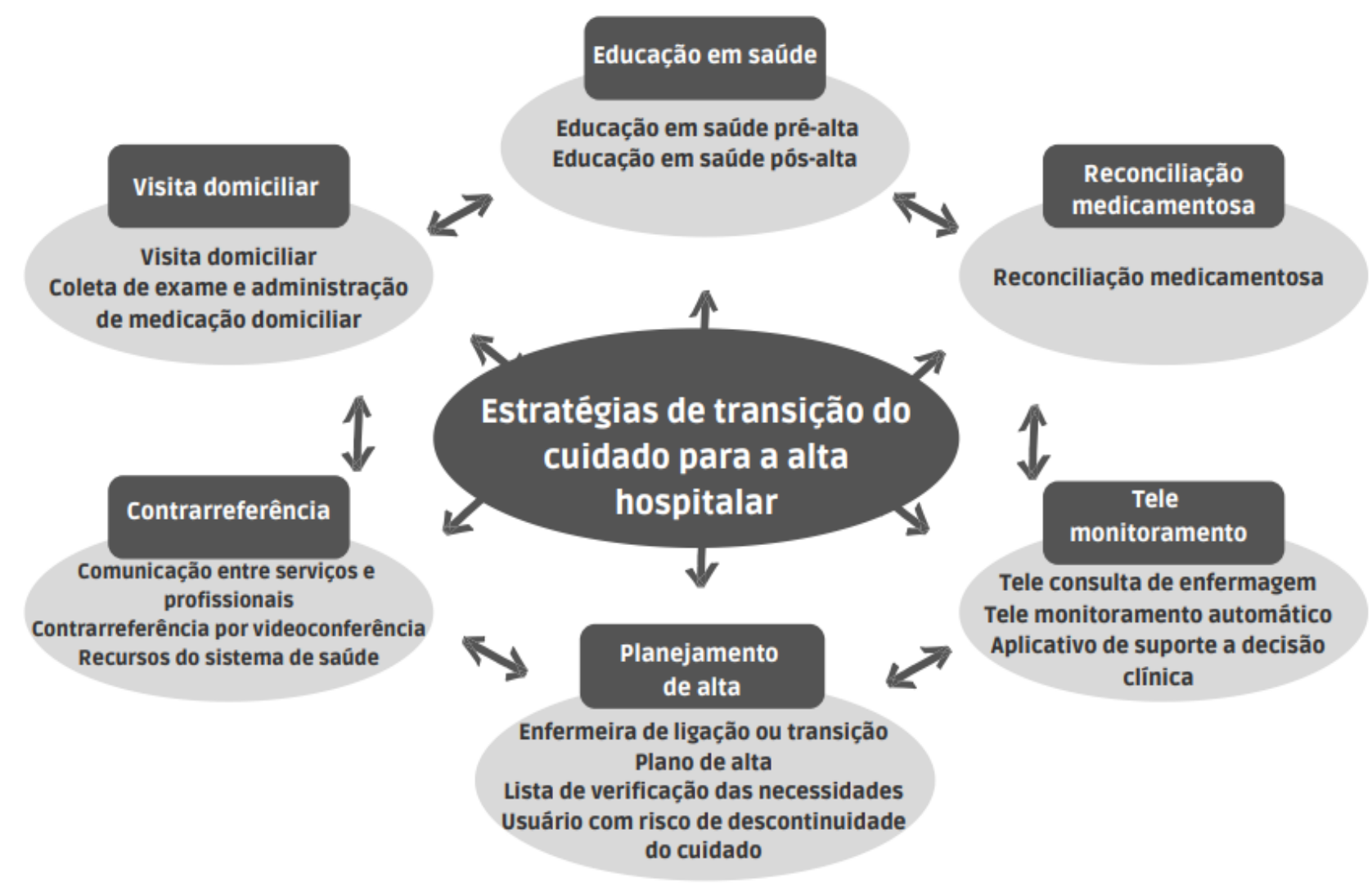

Figura 2 - Categorias iniciais, intermediárias e categoria final (desfecho).

A primeira categoria intermediária traz a educação em saúde como estratégia de transição do cuidado, que consiste nos processos relacionados ao autocuidado, abordados antes e após a alta hospitalar por $16(69,5 \%)$ estudos. A educação em saúde, considerada um conjunto de práticas que contribuem para aumentar a autonomia do usuário para alcançar a saúde, segundo suas necessidades de cuidado, ${ }^{34}$ esteve presente associada a outras estratégias, especialmente após a alta hospitalar.

A educação em saúde foi identificada no período pré-alta com ações de orientações de cuidado, doença e tratamento, ${ }^{11,16,20,23,25,28}$ apoio e orientação de uso de equipamentos de monitoramento ${ }^{13}$ e 
15 | Gallo VCL, Khalaf DKK, Hammerschmidt KSA, Santiago ML, Vendruscolo C

autogestão de medicamentos. ${ }^{22}$ No período pós-alta hospitalar, os enfermeiros desenvolveram orientações de autocuidado e aconselhamento por meio de ligações telefônicas ${ }^{11,14,17,20-22,27,29}$ e visitas domiciliares. $^{21,31,33}$

A segunda categoria intermediária foi a reconciliação medicamentosa, ${ }^{16,18,20-21,33}$ estratégia de comparação da lista completa e detalhada dos medicamentos utilizados com as prescrições em admissões, transferências, consultas ambulatoriais e alta hospitalar. Esta atividade permite a utilização de medicamentos nos momentos de transição do cuidado de forma segura, reduzindo o risco de erros. ${ }^{35}$

O telemonitoramento foi a terceira estratégia utilizada pelos enfermeiros e abrangeu a teleconsulta de enfermagem em tempo real para orientação e avaliação de riscos de descontinuidade do cuidado, ${ }^{11-12,14-15,17-18,20-21,23,26-27,29-30}$ o telemonitoramento automático a partir de software de inteligência artificial com identificação da necessidade de contato em tempo real ${ }^{13,22,31}$ e aplicativos com captação de dados para suporte à decisão clínica. ${ }^{26}$

Como quarta categoria intermediária, está o planejamento da alta, caracterizado como sistematização das atividades determinadas a partir das necessidades e participação do usuário para promover o bem-estar e recursos necessários para garantir assistência segura e continuidade do cuidado. ${ }^{36}$ Para sua efetivação, foram abordadas ações de elaboração de planos, ${ }^{18-19,28}$ uso de lista de verificação de necessidades, ${ }^{19}$ identificação de usuários com maiores riscos de descontinuidade do cuidado e a atuação de enfermeiras de ligação, transição ou navegação. ${ }^{12,15-16,18-20,22-26}$

A quinta categoria foi formada pela contrarreferência, que permitiu uma troca de informações eficaz entre os diferentes serviços de assistência e profissionais de saúde, 15,21-24,26,29 uso de videoconferência para troca de informações ${ }^{19}$ e identificação de recursos da rede de atenção à saúde necessários à continuidade do cuidado. ${ }^{16-17,19,24,28,33}$

A sexta categoria intermediária incluiu a visita domiciliar, que consiste na assistência, acompanhamento e orientação de usuários em suas residências. ${ }^{37}$ Esta categoria esteve presente associada a outras, como educação em saúde, administração de medicamentos e telemonitoramento. ${ }^{16,18,21-23}$ As seis categorias intermediárias conduziram ao desfecho da análise, com a 
Estratégias de transição para alta hospitalar utilizadas por enfermeiros: revisão integrativa | 16 identificação da categoria final: estratégias de transição do cuidado para a alta hospitalar.

\section{Discussão}

As principais estratégias de transição de cuidado voltadas ao fortalecimento da continuidade do cuidado após a alta hospitalar, identificadas na literatura científica, foram educação em saúde, reconciliação medicamentosa, telemonitoramento, planejamento da alta hospitalar, contrarreferência e visita domiciliar. Verificou-se produção constante de estudos sobre o tema entre 2016 e 2019, com redução acentuada em 2020, que necessita ser mais bem compreendida.

Os EUA apresentaram produção expressiva de estudos desenvolvidos na temática da transição do cuidado, especialmente destinados à continuidade do cuidado, voltados à redução de readmissões hospitalares evitáveis para a consequente redução de custos com a saúde. ${ }^{12-22,25-27,29-30,33}$ Esta realidade é justificada pelo sistema de saúde privativista em vigor no país, que procura estratégias de redução de custos e otimização de recursos financeiros. ${ }^{5}$

Também se destacaram periódicos multidisciplinares como principais fontes de divulgação do conhecimento e de estudos sobre as estratégias de transição e continuidade do cuidado (43,5\%), seguidos daqueles especializados em enfermagem. ${ }^{20-21,23,31}$ Esta constatação evidenciou o aspecto multidimensional da temática bem como o aumento do interesse sobre o tema em várias áreas do conhecimento. ${ }^{5}$

Ocorreu predominância de estudos com NE 4 (56,5\%), seguidos de NE 2 (26\%) e NE 6 (17,4\%). Esta realidade comprova a necessidade de aumento do rigor metodológico para fortalecer a prática da transição do cuidado com base em evidência. Todos os artigos incluídos nesta revisão abordaram mais de uma estratégia de transição do cuidado para a alta hospitalar.

Percebeu-se que 16 estudos apresentaram ações de educação em saúde, descritas como orientações pré e pós-alta hospitalar, voltadas, principalmente, ao autocuidado. 11,13-14,16-17,20-23,25,27-31,33 Entre os tópicos abordados, destacaram-se a compreensão da doença e suas complicações, ${ }^{16,30}$ adesão a atividades físicas, ${ }^{11}$ controle de fatores de risco, ${ }^{11,14}$ alívio de sinais e sintomas ${ }^{20-21,29}$ e monitorização de sinais vitais. ${ }^{13}$ Em revisão feita no Canadá, pesquisadores identificaram que a educação em saúde 
17 | Gallo VCL, Khalaf DKK, Hammerschmidt KSA, Santiago ML, Vendruscolo C

aplicada isoladamente como estratégia de transição do cuidado não mostrou impacto positivo na redução de readmissão hospitalar, entretanto, quando associada a outras intervenções, obteve impacto na melhoria da qualidade de vida e adesão ao tratamento proposto. A educação em saúde envolve a construção de conhecimento considerando a participação e a reflexão da realidade. ${ }^{6}$

$\mathrm{Na}$ reconciliação medicamentosa, o enfermeiro desempenha papel ativo na prevenção de discrepâncias relacionadas à segurança e interrupções do tratamento, com consequente redução de agravamento de comorbidades. ${ }^{38}$ Trata-se de estratégia desenvolvida e utilizada nos EUA para melhorar a segurança e a continuidade da terapêutica após a alta. ${ }^{38} \mathrm{~A}$ reconciliação medicamentosa foi empregada em associação com a educação em saúde ${ }^{16,20}$ e a visita domiciliar. ${ }^{16,18,21,23}$

O telemonitoramento utilizado pelos enfermeiros para facilitar e apoiar a continuidade do cuidado esteve presente em dezessete estudos ${ }^{11-15,17-18,20-23,26-27,29-31}$ envolvendo contatos entre enfermeiros e usuários dos sistemas de saúde em tempo real ou por mensagens eletrônicas programadas. Nos últimos anos, o uso de tecnologias de informação e comunicação, em especial por meio de chamadas em dispositivos móveis, vem estando mais presente. Quando associada a estratégias como educação em saúde e visita domiciliar, ela pode auxiliar o sucesso da continuidade do cuidado após a alta hospitalar ${ }^{18,21,23,31}$ por facilitar uma transição de cuidado segura.

Pesquisadores evidenciaram o uso de roteiros estruturados como importantes ao desenvolvimento do telemonitoramento por padronizar a revisão de orientações de autocuidado, manutenção e promoção da saúde. ${ }^{11-12,15,17,20,23,27,29}$ Os roteiros de investigação e orientações pós-alta foram realizados tendo como referência diretrizes de orientações para a alta adotadas pelas instituições. Esta ação foi necessária para facilitar a comunicação entre os enfermeiros nas centrais de monitoramento, os quais desempenharam papel fundamental em programas de monitoramento pós-alta para uma transição de cuidados segura. ${ }^{17-18,21-22,25}$

O planejamento da alta foi observado como parte das atividades dos enfermeiros, com identificação de usuários com riscos de descontinuidade do cuidado, ${ }^{15-16,18,28}$ elaboração de planos de alta $^{19,28}$ e atuação de profissionais especializados em transição de cuidado..$^{12,18-20,22-26,28,32}$ 
Estratégias de transição para alta hospitalar utilizadas por enfermeiros: revisão integrativa | 18

A identificação de usuários com risco de descontinuidade do cuidado e readmissão hospitalar foi importante para otimizar ações adequadas às suas necessidades. Listas de verificação e escores de risco vêm sendo desenvolvidos e usados por profissionais envolvidos na transição do cuidado. ${ }^{15-16,18} \mathrm{~A}$ elaboração de planos de alta auxilia o processo de educação e gerenciamento do autocuidado nos processos de transição do cuidado, fornecendo informações relevantes ao controle de doenças, adesão ao plano terapêutico, controle da dor e uso de equipamentos e insumos de saúde. ${ }^{18-19,28}$ Enfermeiros especializados em processos de transição desenvolvem atividades destinadas a assegurar a coordenação e a continuidade do cuidado entre os serviços de saúde. ${ }^{4}$

A contrarreferência ou troca de informações de saúde entre profissionais e serviços está cada vez mais presente. O uso de prontuários eletrônicos compartilhados, ${ }^{15} \mathrm{o}$ envio de informações da internação à APS por ligações telefônicas, os alertas eletrônicos e formulários de alta ${ }^{21,27-29,31}$ despontam como estratégias eficientes para o fortalecimento da transição e da continuidade do cuidado. A comunicação durante os processos de transição do cuidado criou oportunidade de entrega de informações essenciais, ${ }^{5}$ e o enfermeiro deve persegui-la de maneira eficaz para garantir a segurança do usuário. ${ }^{39}$

Além destas estratégias, houve menção da visita domiciliar, utilizada pelos enfermeiros ligados a APS para implementar a continuidade do cuidado, permitindo conhecimento da dinâmica familiar, adequação e ajuste de orientações de autocuidado, assistência direta e avaliação de riscos psicossociais envolvidos na descontinuidade do cuidado. ${ }^{16,18,21,23,31,33} \mathrm{~A}$ visita domiciliar deve ocorrer de maneira precoce, possibilitando a identificação de alterações com potencial de descompensação clínica para um manejo adequado e redução dos efeitos adversos potenciais no pós-alta. ${ }^{31}$

Como limitação deste estudo, destacam-se a utilização de amostra de artigos científicos dos últimos cinco anos e a utilização de filtros para busca, o que pode restringir os resultados da pesquisa.

\section{Conclusão}

Os resultados destacaram como estratégias de transição do cuidado na alta hospitalar atividades de educação em saúde, reconciliação medicamentosa, telemonitoramento, planejamento de alta, 
19 | Gallo VCL, Khalaf DKK, Hammerschmidt KSA, Santiago ML, Vendruscolo C

contrarreferência e visita domiciliar, realizadas de forma interconectada. O desfecho apresentado no corpus de análise da revisão reforça a relevância da assistência integral ao usuário do sistema de saúde, com prestação da assistência necessária ao longo do tempo, ou seja, a longitudinalidade ou continuidade do cuidado envolvendo diversos níveis dos serviços de atenção à saúde.

O enfermeiro é o profissional chave no desenvolvimento de estratégias de transição do cuidado conectadas, demonstrando sua essencialidade para garantir a continuidade do cuidado. A integração de estratégias possibilita a qualificação do cuidado pelo enfermeiro, sendo, assim, essencial a transição do cuidado na prestação de cuidados pós-alta, integrando usuários, família e prestadores de serviços.

\section{Referências}

1. Mendes FRP, Gemito MLGP, Caldeira EC, Serra IC, Casas-Novas MV. A continuidade de cuidados de saúde na perspectiva dos utentes. Ciênc Saúde Colet. 2017;22(3):841-53. doi: 10.1590/1413-81232017223.26292015

2. Cunha EM, Giovanella L. Longitudinality/continuity of care: identifying dimensions and variables to the evaluation of Primary Health Care in the context of the Brazilian public health system. Ciênc Saúde Colet. 2011;6(Suppl 1):1029-42. doi: 10.1590/S1413-81232011000700036

3. Vargas I, Garcia-Subirats I, Mogollón-Pérez AS, Paepe PD, Silva MRF, Unger JP, et al. Patient perceptions of continuity of health care and associated factors. Cross-sectional study in municipalities of central Colombia and North-eastern Brazil. Health Policy Plan. 2017;32(4):549-62. doi: 10.1093/heapol/czw168

4. Acosta AM, Câmara CE, Weber LAF, Fontenele RM. Nurse's activities in care transition: realities and challenges. Rev Enferm UFPE On Line. 2018;12(12):3190-7. doi: 10.5205/1981-8963-v12i12a231432p3190-3197-2018

5. Carr DD. High-Quality care transitions promote continuity of care and safer discharges. J N Y State Nurses Assoc [Internet]. 2019 [cited $2021 \quad$ Feb 05];46(2):4-9. Available from: https://issuu.com/nystatenursesassociation/docs/nysnajournalv46no2/s/10321671

6. Spall HC, Rahman T, Mytton O, Ramasundarahettige C, Ibrahim Q, Kabali M, et al. Comparative effectiveness of transitional care services in patients discharged from the hospital with heart failure: a systematic review and network meta-analysis. Eur J Heart Fail. 2017;19(11):1427-43. doi: 10.1002/ejhf.765

7. Weber LAF, Lima MADS, Acosta AM, Marques GQ. Care transition from hospital to home: integrative review. Cogitare Enferm. 2017;22(3):e47615. doi: 10.5380/ce.v22i3.47615

8. Ribas EDN, Bernardino E, Larocca LM, Poli PP, Aued GK, Silva CPC. Nurse liaison: a strategy for counterreferral. Rev Bras Enferm. 2018;71(Suppl 1):546-53. doi: 10.1590/0034-7167-2017-0490

9. Ganong LH. Integrative reviews of nursing research. Res Nurs Health. 1987;10(1):1-11. doi: 10.1002/nur.4770100103

10. Melnyk BM, Fineout-Overholt E. Evidence-based practice in nursing \& healthcare: a guide to best practice. 
Estratégias de transição para alta hospitalar utilizadas por enfermeiros: revisão integrativa | 20

2nd ed. Philadelphia: Lippincott Williams \& Wilkins; 2011.

11. Bikmoradi A, Masmouei B, Ghomeisi M, Roshnaei G. Impact of Tele-nursing on adherence to treatment plan in discharged patients after coronary artery bypass graft surgery: a quasi-experimental study in Iran. Int J Med Inform. 2016;86:43-8. doi: 10.1016/j.ijmedinf.2015.12.001

12. Moyer A, McGillen B. Transitioning Patients Across the Care Continuum. Nurse Lead. 2018;16(6):389-92. doi: 10.1016/ j.mnl.2018.07.011

13. Ong MK, Romano PS, Edginton S, Aronow HU, Auerbach AD, Black JT, et al. Effectiveness of remote patient monitoring after discharge of hospitalized patients With heart failure: The Better Effectiveness After Transition Heart Failure (BEAT-HF) randomized clinical trial. JAMA Intern Med. 2016. 176(3):310-8. doi: 10.1001/jamainternmed.2015.7712

14. Phelps P, Sutton K. Structured telephonic consultation to decrease heart failure readmissions. Medsurg Nurs [Internet]. $2018 \quad$ [cited $2021 \quad$ Feb 05$] ; 27(3): 153-72 . \quad$ Available from: https://www.proquest.com/openview/be0aa8f01d43d82fabe75f0db9287b5f/1?pq-origsite=gscholar\&cbl=30764

15. Ruggiri JC, Milner KA, Buonocore D. Implementing post-discharge 48-hour scripted call for patients with heart failure: an evidence-based practice quality improvement project. Medsurg Nurs [Internet]. 2019 [cited 2021 Feb 05];28(3):183-7. Available from: https://www.proquest.com/openview/40722d1745ed79b1ea423e02a0115dbe/1?pq-origsite=gscholar\&cbl=30764

16. Smith J, Pan DM, Novelli MA. Nurse practitioner-led intervention to reduce hospital readmissions. J Nurse Pract. 2016;12(5):311-6. doi: 10.1016/j.nurpra.2015.11.020

17. Biese KJ, Busby-Whitehead J, Cai J, Stearns SC, Roberts E, Milhas P, et al. Telephone follow-up for older adults discharged to home from the emergency department: a pragmatic randomized controlled trial. J Am Geriatr Soc. 2018;66(3):452-8. doi: 10.1111/jgs.15142

18. Dizon ML, Reinking C. Reducing readmissions: nurse-driven interventions in the transition of care from the hospital. Worldviews Evid Based Nurs. 2017;14(6):432-9. doi: 10.1111/wvn.12260

19. Knight SW, Trinkle J, Tschnnen D. Hospital-to-homecare videoconference handoff: improved communication, coordination of care, and patient/family engagement. Home Healthc Now. 2019;37(4):198-207. doi: 10.1097/NHH.0000000000000755

20. Kripalani S, Chen G, Ciampa P, Theobald C, Cao A, McBride M, et al. A transition care coordinator model reduces hospital readmissions and costs. Contemp Clin Trials. 2019;81:55-61. doi: 10.1016/j.cct.2019.04.014

21. Radhakrishnan K, Jones TL, Weems D, Knight TW, Rice WH. Seamless transitions: achieving patient safety through communication and collaboration. J Patient Saf. 2018;14(1):e3-5. doi: 10.1097/PTS.0000000000000168

22. Ritchie CS, Houston TK, Richman JS, Sobko HJ, Berner ES, Taylor BB, et al. The E-Coach technology-assisted care transition system: a pragmatic randomized trial. Transl Behav Med. 2016;6(3):428-37. doi: 10.1007/s13142-0160422-8

23. Spall HGC, Lee SF, Xie F, Oz UE, Perez R, Mitoff PR, et al. Effect of patient-centered transitional care services on clinical outcomes in patients hospitalized for heart failure: the PACT-HF randomized clinical trial. JAMA. 2019;321(8):753-61. doi: 10.1001/jama.2019.0710 
24. Yatim F, Cristofalo P, Ferrua M, Girault A, Lacaze M, Palma MD, et al. Analysis of nurse navigators' activities for hospital discharge coordination: a mixed method study for the case of cancer patients. Support Care Cancer. 2017;25(3):863-8. doi: 10.1007/s00520-016-3474-x

25. Hardiman KM, Reames CD, Mcleod MC, Regenbogen SE. Patient autonomy-centered self-care checklist reduces hospital readmissions after ileostomy creation. Surgery. 2016;160(5):1302-8. doi: 10.1016/j.surg.2016.05.007

26. Hewnwe S, Sullivan SS, Yu G. Reducing emergency room visits and in-hospitalizations by implementing best practice for transitional care using innovative technology and big data. Worldviews Evid Based Nurs. 2018;15(3):170-7. doi: 10.1111/wvn.12286

27. Anronoff MB, Ragalie W, Correa AM, Spicer JD, Sepesi B, Roth JA, et al. Results of postdischarge nursing telephone assessments: persistent symptoms common among pulmonary resection patients. Ann Thorac Surg. 2016;102(1):276-81. doi: 10.1016/j.athoracsur.2016.01.062

28. Aued GK, Bernardino E, Lapierre J, Dallaire C. Liaison nurse activities at hospital discherge: a strategy for continuity of care. Rev Latinoam Enferm. 2019;27:e3162. doi: 10.1590/1518-8345.3069-3162

29. Auger KA, Shah SS, Tubbs-Cooley HL, Sucharew HJ, Gold JM, Wade-Murphy S, et al. Effects of a 1-Time nurse-led telephone call after pediatric discharge: the H2O II randomized clinical trial.JAMA Pediatr. 2018;172(9):e181482. doi: doi: 10.1001/jamapediatrics.2018.1482

30. Hastings SN, Stechuchak KM, Coffman CJ, Mahanna EP, Weunberger M, Houtven CHV, et al. Discharge information and support for patients discharged from the emergency department: results from a randomized controlled trial. J Gen Intern Med. 2020;35(1):79-86. doi: 10.1007/s11606-019-05319-6

31. Pacho C, Domingo M, Núñez R, Lupón J, Moliner P, Antonio A, et al. Una consulta específica al alta (STOPHF-Clinic) reduce los reingresos a 30 días de los pacientes ancianos y frágiles con insuficiencia cardiaca. Rev Esp Cardiol. 2017;70(8):631-8. doi: 10.1016/j.recesp.2016.12.026

32. Ribas EN, Bernardino E, Larocca LM, Poli Neto P, Aued GK, Silva CPC. Nurse liaison: a strategy for counterreferral. Rev Bras Enferm. 2018;71(Suppl 1):546-53. doi: 10.1590/0034-7167-2017-0490

33. Wells S, O'Neill M, Rogers J, Blaine K, Hoffman A, McBride S, et al. Nursing-led home visits posthospitalization for children with medical complexity. J Pediatr Nurs. 2017;34:10-6. doi: 10.1016/j.pedn.2017.03.003

34. Ministério da Saúde (BR), Secretaria de Gestão do Trabalho e da Educação na Saúde, Departamento de Gestão e da Regulação do Trabalho em Saúde. Câmara de Regulação do Trabalho em Saúde. Brasília (DF): Ministério da Saúde; 2006.

35. World Health Organization (WHO). Medication without harm: WHO global patient safety challenge [Internet]. Geneva (CH): WHO; $2017 \quad$ [cited $2021 \quad$ Feb 05]. Available from: http://apps.who.int/iris/bitstream/10665/255263/1/WHO-HIS-SDS-2017.6- eng.pdf?ua=1

36. Lemos DMP, Saldanha PF, Vieira LF, Azzolin KO. Nursing taxonomies in hospital discharge planning: a quasi-experimental study. Rev Bras Enferm. 2020;73(5):e20180896. doi: 10.1590/0034-7167-2018-0896

37. Cunha LP, Silva FVC, Santos FK, Pires AS, Leone DRR, Silva LCS. The home visit in peritoneal dialysis: relevant aspects to nursing care. Rev Pesq Cuid Fundam. 2017;9(1):128-36. doi: 10.9789/2175-5361.2017.v9i1.128-136 38. Lombardi NF, Mendes AEM, Lucchetta RC, Reis WCT, Fávero MLD, Correr CJ. Analysis of the discrepancies 
Estratégias de transição para alta hospitalar utilizadas por enfermeiros: revisão integrativa | 22

identified during medication reconciliation on patient admission in cardiology units: a descriptive study. Rev Latinoam Enferm. 2016;24:e2760. doi: 10.1590/1518-8345.0820.2760

39. Jackson, ML. Transitional care: methods and processes for transitioning older adults with cancer in a postacute settin. Clin J Oncology Nurs. 2018;22(6):37-41. doi: 10.1188/18.CJON.S2.37-41

Editora Científica Chefe: Cristiane Cardoso de Paula

Editora Associada: Etiane de Oliveira Freitas

\section{Autor correspondente}

Karina Silveira de Almeida Hammerschmidt

E-mail: ksalmeidah@ufpr.br

Endereço: Rua 24 de maio, 980, Apartamento 704 - Bairro: Rebouças; Cidade: Curitiba; Estado: Paraná. CEP: 80220-060

\section{Contribuições de Autoria}

1 - Valéria Cristina Lopes Gallo

Concepção ou desenho do estudo/pesquisa; (2) análise e/ou interpretação dos dados (3) revisão final com participação crítica e intelectual no manuscrito.

\section{2 - Daiana Kloh Khalaf}

Concepção ou desenho do estudo/pesquisa; (3) revisão final com participação crítica e intelectual no manuscrito).

\section{3 - Karina Silveira de Almeira Hammerschmidt}

Concepção ou desenho do estudo/pesquisa; (3) revisão final com participação crítica e intelectual no manuscrito.

\section{4 - Mariane Lima Santiago}

Análise e/ou interpretação dos dados

\section{5 - Carine Vendruscolo}

Revisão final com participação crítica e intelectual no manuscrito

\section{Como citar este artigo}

Gallo VCL, Khalaf DK, Hammerschmidt KSA, Santiago ML, Vendruscolo C. Estratégias de transição para alta hospitalar utilizadas por enfermeiros: revisão integrativa Rev. Enferm. UFSM. 2021 [Acesso em: Anos Mês Dia]; vol.11 e79: 1-22. DOI: https://doi.org/10.5902/2179769264383 